\title{
PENERAPAN MODEL PENCEGAHAN DEPRESI POSTPARTUM-RATU DI PUSKESMAS PUTRI AYU KELURAHAN LEGOKKECAMATAN DANAU SIPIN KOTA JAMBI
}

\section{THE IMPLEMENTATION OF PREVENTION POSTPARTUM DEPRESSION RATU'S- MODEL IN PUTRI AYU HEALTH CENTER, LEGOK, DANAU SIPIN JAMBI CITY}

\author{
Ratu Kusuma $^{1)^{*}}$, Tina Yuli Fatmawati ${ }^{2}$ \\ ${ }^{1)}$ Prodi Ners, STIKes Baiturrahim, email: ratukusuma1975@gmail.com \\ ${ }^{2)}$ Prodi D3 Keperawatan, STIKes Baiturrahim, email: tinayulifatmawati@yahoo.com
}

\begin{abstract}
ABSTRAK
Depresi postpartum adalah gangguan psikologis pada ibu pasca-melahirkan dengan kejadian di dunia mencapai 20\%, Indonesia (Riau 18,52\%, Medan 16-36\%, Palembang 13,3\%, dan Jambi 13\%), angka ini harus ditekan menjadi $1 \%$ bahkan dihilangkan. Pelayanan Antenatal Terpadu yang selama ini diterapkan di Puskesmas Putri Ayu Kota Jambi adalah Komunikasi, Informasi dan Edukasi Efektif dan Kelas Ibu Hamil. KIE umumnya diberikan melalui konsultasi perorangan saat ibu melakukan kunjungan antenatal; belum semua ibu hamil yang mengikuti Kelas Ibu Hamil dan belum menghadirkan suami pada Kelas Ibu Hamil Kegiatan antenatal dikoordinir dan dilaksanakan oleh bidan, perawat hanya sebagai tenaga pendamping lintas program. Model Pencegahan Depresi Postpartum-Ratu merupakan produk disertasi penulis yang belum pernah diterapkan di Provinsi Jambi, merupakan model edukasi untuk ibu hamil dan suami dalam pencegahan depresi perinatal. Kegiatan pengabdian ini telah dilakukan pada Mei-Juli 2019 dengan metode survei, ceramah, diskusi, dan tanya jawab. Hasil yang dicapai adalah terbentuknya kader, terlaksananya pelatihan kader dan eduksi kepada ibu hamil dan suami. Peningkatan rerata pengetahuan ibu hamil sebesar 2,38; peningkatan rerata sikap 4,60, peningkatan rerata respons adaptasi ibu hamil (fisiologis 1,76; konsep diri 3,36; fungsi peran 2,49, dan interdependent 2,24) dan peningkatan rerata dukungan suami 3,84 setelah diberikan edukasi model.
\end{abstract}

Kata kunci: Model, Pencegahan, Depresi, Postpartum-Ratu

\section{ABSTRACT}

Postpartum depression is a psychological disorder in postpartum women, incidence in the world 20\%, Indonesia (Riau 18.52\%, Medan 16-36\%, Palembang 13.3\%, and Jambi 13\%), this number should be reduced to $1 \%$ even eliminated. Intenatal care that have so far been applied at Puskemsmas Putri Ayu in Kota Jambi. Information, education and communicationis generally given through individual consultation when the pregnant women makes antenatal visits; not all pregnant women do it the prenatal class and have not presented their husbands inclass. Antenatal activities are coordinated by midwives, nurses are only assistants. The Ratu's Modelis a product of dissertation from first author's that has never been applied in Jambi Province, it is an educational model for pregnant women and husbands in the prevention perinatal depression. This dedication activity was carried out in May-July 2019 using survey, lecture, discussion, and question and answer methods. The results achieved were the formation of cadres, the implementation of cadre training and education for pregnant women and husbands. Increased mean knowledge of pregnant women 2.38; attitude 4.60, adaptation response of pregnant women (physiological 1.76; selfconcept 3.36; role function 2.49, and interdependent 2.24) andsupport of husband 3.84 after the model education was given.

Keywords: The Ratu's Model: Prevention Postpartum Depression 
PENDAHULUAN

Depresi postpartum merupakan salah satu gangguan psikolologis pada ibu pascamelahirkan dengan kejadian di dunia mencapai 20\%, Indonesia (Riau 18,52\% [1], Medan 16$36 \%$ [2], Palembang 13,3\% [3], Jambi 13\% [4]), angka ini masih jauh lebih besar dibandingkan dengan target bahwa depresi postpartum harus ditekan menjadi $1 \%$ bahkan dihilangkan [5]. Salah satu faktor yang mempengaruhi terjadinya depresi postpartum adalah rendahnya cakupan K1 dan K4. Ibu yang melakukan kunjungan antenatal $<2$ kali berisiko 5,7 kali melahirkan bayi BBLR, faktor tersebut berkontribusi terhadap terjadinya depresi postpartum [6], [7]. Jambi merupakan salah satu provinsi yang belum mencapai cakupan kunjungan antenatal care, cakupan K458,06\% (standar nasional 84\%) [8].

Berdasarkan wawancara dengan beberapa ibu hamil dan suami, adanya anggapan bahwa perubahan mood pada masa kehamilan dan postpartum seperti perasaan sedih, marah, cemas, takut, bingung, panik, marah, gangguan tidur, perubahan nutrisi, perubahan berat badan, penurunan libido, dll, merupakan hal yang biasa pada wanita hamil dan tidak perlu mendapat perhatian keluarga dan tenaga kesehatan karena akan hilang dengan sendirinya. Selain itu, beberapa ibu hamil yang menunjukkan gejala gangguan psikologis seperti tidak menginginkan kehamilannya, ingin menggugurkan bahkan telah melakukan upaya untuk menggugurkan kehamilannya (Personal
Komunikasi dengan ibu hamil dan suamisuami, Agustus 2018).

Pelayanan antenatal terpadu yang selama ini diterapkan di Puskesmas Putri Ayu adalah dalam bentuk Komunikasi, Informasi dan Edukasi Efektif dan Pelaksanaan Kelas Ibu Hamil. KIE umumnya diberikan melalui konsultasi perorangan saat ibu melakukan kunjungan antenatal;belum semua ibu hamil yang mengikuti Kelas Ibu Hamil dan belum menghadirkan suami pada Kelas Ibu Hamil (Personal Komunikasi dengan Koordinator Perawat Puskesmas Putri Ayu, 14 Juli 2018).

Pelaksanaan Pelayanan Antenatal Terpadu di Puskesmas Putri Ayu menjadi tanggung jawab bidan, dilaksanakan dan dikoordinir oleh bidan, perawat hanyasebagai tenaga pendamping lintas program.

Model pencegahan depresi postpartum merupakan produk disertasi ketupengusul, yang dikembangkan dari Model Adaptasi Calista Roy. Merupakan model edukasi yang diberikan kepada ibu hamil dan suami, bertujuan meningkatkan pengetahuan, perubahan sikap, perubahan respons perilaku adaptasi ibu hamil, peningkatan dukungan sosial suami dalam upaya mencegah terjadinya depresi perinatal (kehamilan hingga postpartum). Bentuk Model Pencegahan Depresi Postpartum-Ratu adalah: 


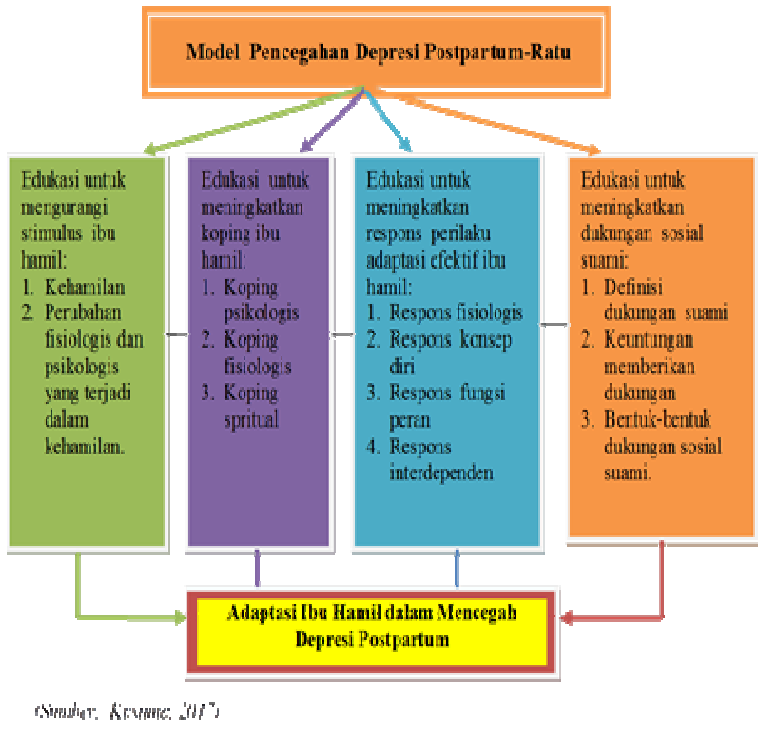

Skema 1. Bentuk Model Depresi PostpartumRatu

Berdasarkan permasalahan tersebut, Model Pencegahan Depresi Postpartum-Ratu diharapkan dapat disosialisasikan kepada perawat dan dapat terapkan kepada ibu hamil dan suami di Puskesmas Putri Ayu Jambi. Model ini sebelumnya sudah diterapkan kepada ibu hamil dan suami di 2 (dua) Puskesmas di Provinsi Riau, hasilnya efektif menurunkan kejadian depresi postpartum sebanyak $60 \%$.

\section{METODE PELAKSANAAN KEGIATAN}

Metode pelaksanaan kegiatan ini meliputi:

1) Pra-interaksi: pendekatan dengan pihak terkait, memilih calon peserta pelatihan kader, pembentukan struktur organisasi,serta persiapan alat dan bahan.
2) Interaksi: pembentukan dan pelatihan kader terpilih serta penerapan model kepada ibu hamil dan suami melalui edukasi kelompok.

3) Melakukan pendampingan terhadap kemampuan perawat menerapakan model kepada ibu dan suami.

4) Melakukan monitoring dan evaluasi terhadap semua kegiatan yang telah dilakukan.

\section{HASIL DAN PEMBAHASAN}

Kegiatan PKM ini telah dilakukan pada Mei-Juli 2019, meliputi:

1. Pertemuan dengan aparat terkait: Kapus, Ka.TU, Koordinator Perawat, bidan penanggung jawab Poliklinik KIA.

2. Pertemuan dengan perawat calon peserta pelatihan kader.

3. Mengidentifikasi kembali data ibu hamil Trimester III kepada Bidan Penanggung jawab Poliklinik KIA.

4. Pembentukan dan Pelatihan Kader. Peserta pelatihan kader adalah 10 perawat dan 1 bidan penanggung jawab Poliklinik KIA,kader dilakukan selama 3 hari (18-20 Juli 2019).

Materi ditampilkan dalam bentuk power point, dan semua materi tersebut terdapat pada perangkat model yang telah dibagikan kepada peserta pelatihan. Pengisian kuesioner dipaparkan melalui slide, dibahas satu per satu setiap item pernyataan, termasuk cara penilaiannya. Selama kegiatan pelatihan berlangsung, banyak sekali pertanyaan yang 
disampaikan oleh perawat tentang model yang dipaparkan, baik terkait materi, berbagai kuisioner yang digunakan dan cara pengisaan kuisioner. Perawat juga mengemukakan pengalamannya saat memberikan pelayanan dan pengalaman hamilnya.

Tabel 1. Perawat yang Mengikuti Pelatihan

\begin{tabular}{|l|l|l|l|}
\hline No & Nama & $\begin{array}{l}\text { Pendidikan } \\
\text { Terakhir }\end{array}$ & \multicolumn{1}{|c|}{ Jabatan } \\
\hline 1 & Ana & $\begin{array}{l}\text { S1 Kep, } \\
\text { Ns }\end{array}$ & $\begin{array}{l}\text { Koordinator } \\
\text { Perawat }\end{array}$ \\
\hline 2 & Hj. Diana & $\begin{array}{l}\text { S1 Kep, } \\
\text { Ns }\end{array}$ & $\begin{array}{l}\text { Perawat } \\
\text { Pelaksana }\end{array}$ \\
\hline 3 & Eva F & S1 Kep & $\begin{array}{l}\text { Perawat } \\
\text { Pelaksana }\end{array}$ \\
\hline 4 & Mita S & D3 Kep & $\begin{array}{l}\text { Perawat } \\
\text { Pelaksana }\end{array}$ \\
\hline 5 & Maria HS & D3 Kep & $\begin{array}{l}\text { Perawat } \\
\text { Pelaksana }\end{array}$ \\
\hline 6 & Erni M & D3 Kep & $\begin{array}{l}\text { Perawat } \\
\text { pelaksana }\end{array}$ \\
\hline 7 & Yuliana P & D3 Kep & $\begin{array}{l}\text { Perawat } \\
\text { Pelaksana }\end{array}$ \\
\hline 8 & Lindawati & D3 Kep & $\begin{array}{l}\text { Perawat } \\
\text { Pelaksana }\end{array}$ \\
\hline 9 & Erwis H & D3 Kep & $\begin{array}{l}\text { Perawat } \\
\text { Pelaksana }\end{array}$ \\
\hline 10 & $\begin{array}{l}\text { Nurjanah } \\
\text { L }\end{array}$ & D3 Kep & $\begin{array}{l}\text { Perawat } \\
\text { Pelaksana }\end{array}$ \\
\hline
\end{tabular}

Dokumentasi kegiatan pelatihan kader dapat dilihat pada gambar-gambar berikut:

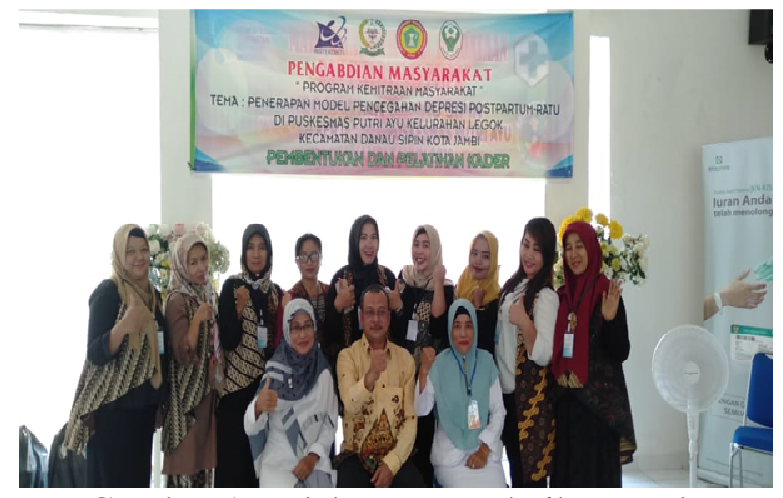

Gambar 1. Pelaksanaan Pelatihan Kader

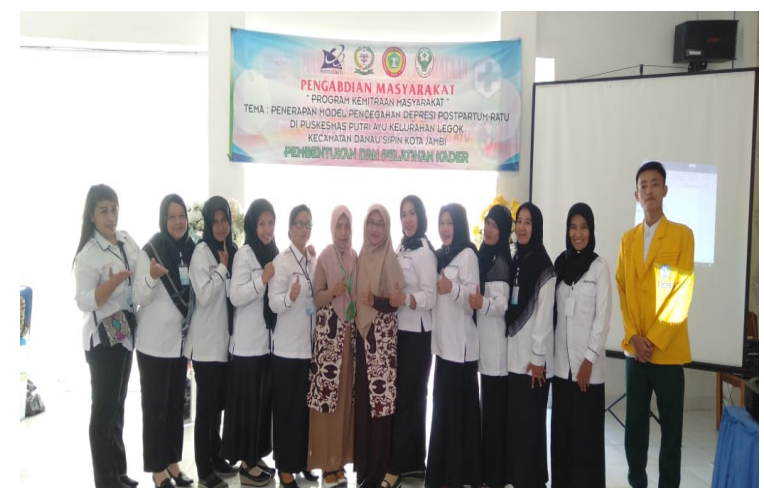

Skema 2. Struktur Organisasi Kader Pelaksana Model Pencegahan Depresi Postpartum-Ratu di Puskesmas Putri Ayu Kota Jambi

5. Melakukan kegiatan penerapan model berupa pemberian edukasi kepada ibu hamil dan suami selama 3 kali pertemuan (29-31 Juli 2019). Kegiatan ini dilakukan bersama 10 perawat yang telah dilatih sebelumnya. Edukasi diberikan kepada 10 ibu hamil trimester III yang didampingi suami saat edukasi berlangsung. Sebelum edukasi, terlebih dahulu dilakukan (prettest), meliputi: identitas (ibu dan suami), pengetahuan dan sikap ibu hamil tentang kehamilan dan berbagai perubahan selama kehamilan, perilaku adaptasi ibu hamil serta kondisi 
depresi ibu. Identifikasi terhadap suami adalah dukungan suami kepada ibu hamil.

Edukasi kepada ibu hamil dan suami dilakukan melalui kelompok, dimana ibu didampingi oleh suaminya. Materi dipaparkan menggunakan power pointdan sebelumnya kepada ibu dan suami dibagikan booklet yang berisi semua materi. Selain booklet, ibu dan suami diberikan buku kerja ibu dan suami yang akan diisi di rumah sebagai proses evaluasi.

Selama pelaksanaan edukasi, beberapa ibu hamil memberikan pertanyaan dan menceritakan pengalaman hamil mereka. Selain itu, beberapa suami juga memberikan pertanyaan dan berbagi pengalaman,

Tabel 2. Karekteristik Ibu dan Suami yang Mengikuti Edukasi Model

\begin{tabular}{|l|l|l|l|l|l|}
\hline No & $\begin{array}{l}\text { Nama } \\
\text { Initial }\end{array}$ & $\begin{array}{l}\text { Usia } \\
\text { Ibu } \\
\text { thn) }\end{array}$ & $\begin{array}{l}\text { Pendi } \\
\text { dikan }\end{array}$ & $\begin{array}{l}\text { Usia } \\
\text { Kehami } \\
\text { lan } \\
\text { (mggu) }\end{array}$ & $\begin{array}{l}\text { Suami/ } \\
\text { usia } \\
\text { (thn) }\end{array}$ \\
\hline 1 & Ny. P & 33 & SD & 39 & Tn. D/37 \\
\hline 2 & Ny. Y & 28 & SD & 35 & Tn. R/33 \\
\hline 3 & Ny. NS & 22 & SMA & 37 & Tn. B/23 \\
\hline 4 & Ny. DS & 34 & SMP & 36 & $\begin{array}{l}\text { Tn. } \\
\text { DZ/32 }\end{array}$ \\
\hline 5 & Ny. K & 41 & SMP & 33 & Tn. M/44 \\
\hline 6 & Ny. AL & 29 & SMP & 34 & Tn. I/29 \\
\hline 7 & Ny. I & 21 & SMA & 35 & $\begin{array}{l}\text { Tn. } \\
\text { AM/22 }\end{array}$ \\
\hline 8 & Ny. M & 38 & SMP & 34 & Tn. H/42 \\
\hline 9 & Ny. L & 28 & SD & 32 & Tn. TR/30 \\
\hline 10 & Ny. MS & 35 & PT & 36 & $\begin{array}{l}\text { Tn. } \\
\text { ZK/36 }\end{array}$ \\
\hline & & & & &
\end{tabular}

Tabel 3. Perubahan Pengetahuan, Sikap, Perilaku Adaptasi Ibu Hamil dan Dukungan Suami Setelah Diberikan Edukasi Model

\begin{tabular}{|l|c|c|c|}
\hline Variabel & $\begin{array}{c}\text { Pre- } \\
\text { edukasi }\end{array}$ & $\begin{array}{c}\text { Post- } \\
\text { Edukasi }\end{array}$ & $\begin{array}{c}\text { Beda } \\
\text { Rata2 }\end{array}$ \\
\cline { 2 - 3 } & Rata2 & Rata2 & \\
\hline Pengetahuan & 12,04 & 14,42 & 2,38 \\
\hline Sikap & 57,04 & 61,64 & 4,60 \\
\hline Respons Adaptasi & \multicolumn{3}{|c|}{} \\
\hline 1) Fisiologis & 34,52 & 36,28 & 1,76 \\
\hline 2) Konsep Diri & 31,08 & 34,44 & 3,36 \\
\hline $\begin{array}{c}\text { 3) Fungsi } \\
\text { Peran }\end{array}$ & 17,26 & 19,75 & 2,49 \\
\hline $\begin{array}{c}\text { 4) Interdepend } \\
\text { en }\end{array}$ & 20,24 & 22,48 & 2,24 \\
\hline Dukungan Suami & 46,40 & 50,24 & 3,84 \\
\hline
\end{tabular}

Tabel 3 menggambarkan bahwa terjadi peningkatan rerata pengetahuan ibu hamil sebesar 2,38; peningkatan rerata sikap 4,60, peningkatan rerata adaptasi fisiologis 1,76; konsep diri 3,36; fungsi peran 2,49, interdependent 2,24 dan dukungan suami 3,84 setelah diberikan edukasi model selama 3 kali pertemuan.

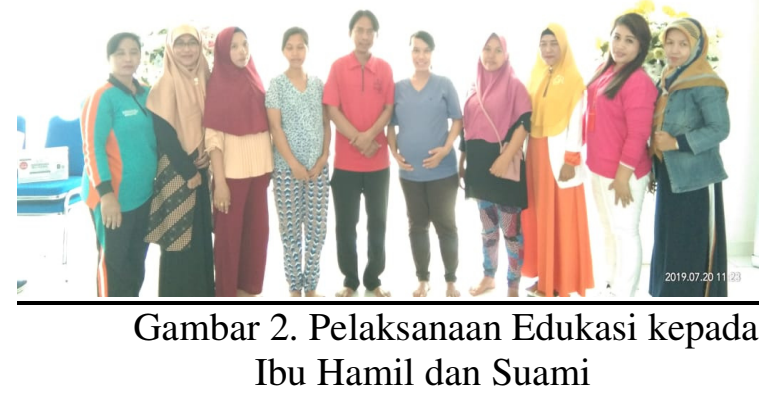




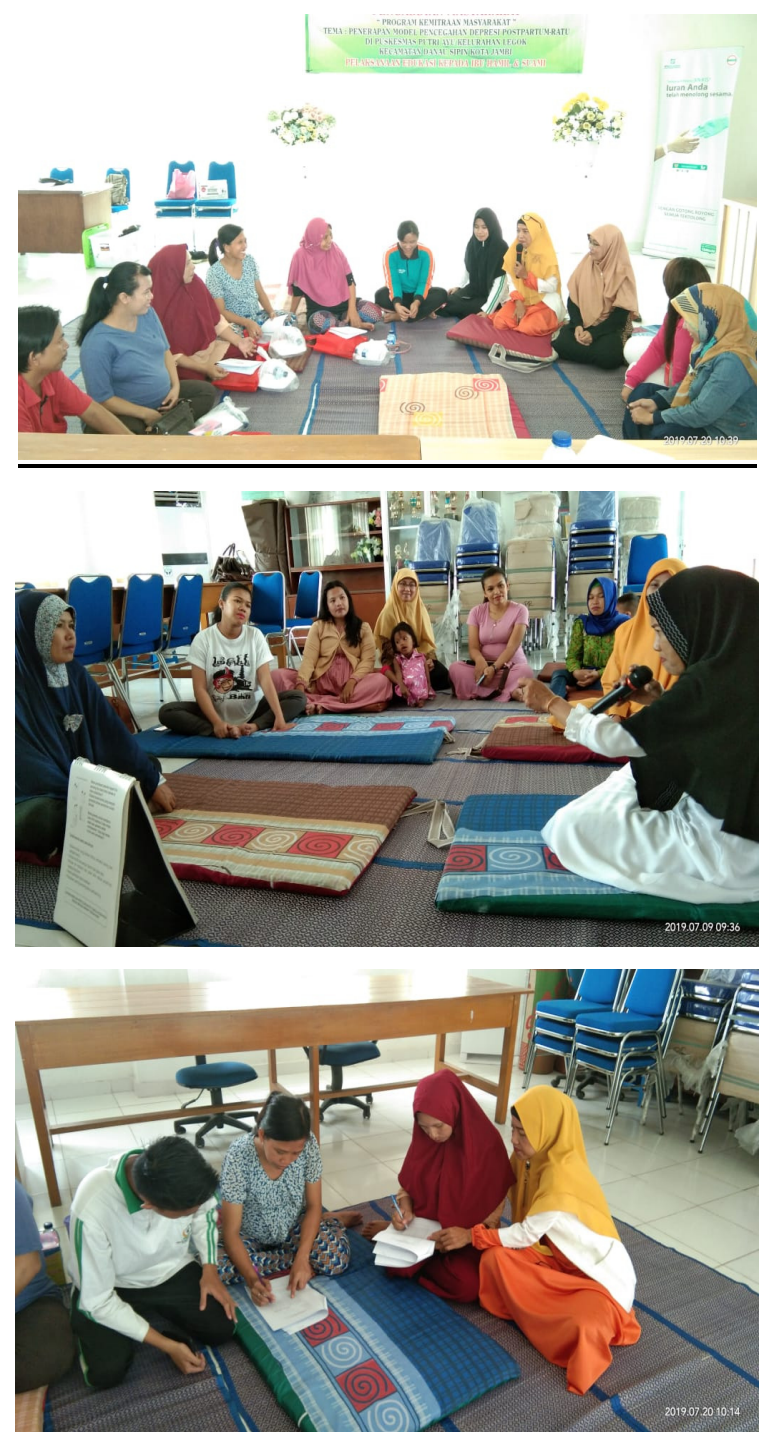

Kegiatan PKM sudah dipublikasikan pada media online Kota Jambi, yaitu Kajanglako (Minggu, 21 Juli 2019)dan Jambi Update.co (Rabu, 24 Juli 2019) serta Media Cetak Jambi Ekspres (Kamis, 24 Juli 2019).

Pendidikan kesehatan adalah upaya promotif dan preventif melalui penyebaran informasi dan meningkatan motivasi seseorang atau masyarakat untuk berperilaku sehat, agar masyarakat mengetahui bagaimana cara memelihara kesehatan, mencegah hal-hal yang merugikan kesehatan serta kemana mencari pertolongan jika mengalami masalah kesehatan ${ }^{9}$. Informasi yang diperoleh ibu saat melakukan kunjungan antenatal berpengaruh terhadap penurunan kejadian depresi karena ibu memiliki koping positif [6].

\section{KESIMPULAN}

Kegiatan pengabdian ini dapat dilaksanakan sesuai rencanayaitu pelatihan kader serta penerapan model kepada ibu hamil dan suami melalui edukasi kelompok. Evaluasi telah dilakukan sesuai tujuan pelaksanaan kegiatan PKM ini.

\section{SARAN}

Saran ditujukan kapada pimpinan puskesmas dan pihak terkait serta perawat yang telah dilatih untuk dapat menerapkan Model Pencegahan Depresi Postpartum-Ratu secara berkelanjutan dalam upaya peningkatan pelayanan kesehatan kepada ibu perinatal sehingga depresi dapat dicegah.

\section{UCAPAN TERIMA KASIH}

Terimakasih kami sampaikan kepada Kemenristekdikti yang telah mendanai kegiatan ini, Ketua STIKes Baiturrahim, Ketua PPPM, Puskesmas Putri Ayu, peserta pelatihan serta ibu hamil dan suami yang telah berpartisipasi dalam kegiatan ini.

\section{DAFTAR PUSTAKA}

[1] Kusuma, R. 2017. Efektifitas Model Pencegahan Depresi Postpartum-Ratu terhadap Pencegahan Depresi PostpartumRatu. Disertasi Program Doktor Ilmu Keperawatan FIK-Universitas Indonesia. Depok: Universitas Indonesia.

[2] Soep. 2011. Penerapan edinburgh postpartum depression scale sebagai alat 
deteksi risiko depresi nifas pada primipara dan multipara. Jurnal Keperawatan Indonesia (JKI), 14 (2).

[3] Girsang, B.M.2013. Pengobatan perilaku kognitif untuk depresi postpartum. Kesmas Nasional Public Health Journal,8 (1).

[4] Suryati, Y. 2013. Hubungan tipe kepribadian dan karakteristik ibu dengan postpartum blues. Jurnal Poltekkes Jambi, (8) 1.

[5] Beck, C.T., Reynold, M.A., \& Rutoewski, R. 2013. Maternity blues and postpartum depression. Journal of Obstetric Gynecologic and Neonatal Nursing, 21
(4). $42-48$.

[6] Leigh, B., \& Migrom, J. 2006. Acceptability of antenatal screening for depression in routine antenatal care. Australian Journal of Advanced Nursing, 24 (3),

[7] Kementerian Kesehatan Republik Indonesia. 2018. Riset kesehatan dasar 2018. Jakarta: Kemenkes RI.

[8] Kementerian Kesehatan Republik Indonesia. 2016. Peraturan menteri kesehatan Republik Indonesia Nomor 43 Tahun 2016. Jakarta: Kemenkes RI.

[9] Notoatmodjo,S. 2014. Perilaku kesehatan. Jakarta:

Rineka

Cipta. 